\title{
Defective hepatic regeneration after partial hepatectomy in leptin-deficient mice is not rescued by exogenous leptin
}

\author{
Isabelle A Leclercq ${ }^{1}$, Matthieu Vansteenberghe ${ }^{2}$, Valérie B Lebrun ${ }^{1}$, Noémi K VanHul ${ }^{1}$, \\ Jorge Abarca-Quinones ${ }^{1}$, Christine L Sempoux ${ }^{3}$, Chirstian Picard ${ }^{1}$, Peter Stärkel ${ }^{1}$ \\ and Yves L Horsmans ${ }^{1}$ \\ ${ }^{1}$ Laboratory of Gastroenterology, Faculty of Medicine, Université Catholique de Louvain, Brussels, Belgium; \\ ${ }^{2}$ Laboratory of Experimental Surgery, Faculty of Medicine, Université Catholique de Louvain, Brussels, \\ Belgium and ${ }^{3}$ Department of Pathology, Faculty of Medicine, Université Catholique de Louvain, Brussels, \\ Belgium
}

\begin{abstract}
Liver regeneration after partial hepatectomy $(\mathrm{PH})$ is impaired in leptin-deficient ob/ob mice. Here, we tested whether exogenous leptin and/or correction of the obese phenotype (by food restriction or long-term leptin administration) would rescue hepatocyte proliferation and whether the hepatic progenitor cell compartment was activated in leptin-deficient ob/ob livers after $\mathrm{PH}$. Because of the high mortality following $70 \% \mathrm{PH}$ to ob/ob mice, we performed a less extensive $(55 \%)$ resection. Compared to lean mice, liver regeneration after $55 \% \mathrm{PH}$ was deeply impaired and delayed in ob/ob mice. Administration of exogenous leptin to ob/ob mice at doses that restored circulating leptin levels during the surgery and postsurgery period or for 3 weeks prior to the surgical procedure did not rescue defective liver regeneration. Moreover, correction of obesity, metabolic syndrome and hepatic steatosis by prolonged administration of leptin or food restriction (with or without leptin replacement at the time of $\mathrm{PH}$ ) did not improve liver regeneration in ob/ob mice. The hepatic progenitor cell compartment was increased in ob/ob mice. However, after PH, the number of progenitor cells decreased and signs of proliferation were absent from this cell compartment. In this study, we have conclusively shown that neither leptin replacement nor amelioration of the metabolic syndrome, obese phenotype and hepatic steatosis, with or without restitution of normal circulating levels of leptin, was able to restore replicative competence to ob/ob livers after PH. Thus, leptin does not directly signal to liver cells to promote hepatocyte proliferation, and the obese phenotype is not solely responsible for impaired regeneration.

Laboratory Investigation (2006) 86, 1161-1171. doi:10.1038/labinvest.3700474; published online 18 September 2006
\end{abstract}

Keywords: liver steatosis; leptin; partial hepatectomy; liver regeneration; hepatic oval cells; metabolic syndrome

Hepatocyte proliferation is an adaptative response to loss of liver mass and to hepatocellular injury in an attempt to preserve function. It is thus an important factor in pathogenesis and prognosis of all liver diseases. The most commonly used and best-studied model of regeneration is partial hepatectomy $(\mathrm{PH})$ after which remaining mature hepatocytes are replicating, leading to compensatory growth of the organ. ${ }^{1}$ A similar proliferative response of the hepatocytes is observed after necrosis and sustained inflammation of a significant portion

Correspondence: Dr IA Leclercq, MD, PhD, Laboratoire de Gastroentérologie, Université Catholique de Louvain, GAEN 53/79, Avenue E Mounier 53, Brussels B-1200, Belgium.

E-mail: isabelle.leclercq@gaen.ucl.ac.be

Received 14 April 2006; revised 12 July 2006; accepted 22 July 2006; published online 18 September 2006 of the liver parenchyma by chemicals such as $\mathrm{CCl}_{4} \cdot{ }^{1,2}$ It is believed that, when the ability of hepatocytes to divide and replace damaged tissue is compromised, a subpopulation of liver progenitor cells (also called oval cells) are induced to proliferate, and might represent a facultative source for mature liver cells. ${ }^{3-5}$

Animals with disrupted leptin signalling (leptindeficient $o b / o b$ mice or leptin-resistant fatty Zucker rats) exhibit obesity, severe hepatic steatosis and insulin resistance ${ }^{6-9}$ and are exquisitely sensitive to $\mathrm{PH}$ since this surgical procedure is associated with a high mortality and impaired liver regeneration, if the animal survives. ${ }^{10,11}$ Similarly, hepatocyte proliferation is almost absent in the liver of $o b / o b$ mice after induction of significant hepatic necrosis by a single $\mathrm{CCl}_{4}$ injection. ${ }^{12}$ In all cases, a block in hepatocyte cell cycle at the transition between G1 
and S phase has been observed. ${ }^{10-12}$ The mechanism(s) implicated in this perturbation of liver regeneration have not yet been fully identified.

It has been suggested that disrupted lipid metabolism and severe steatosis could be responsible for defective capacity for hepatocyte proliferation. ${ }^{10,11,13}$ However, experimental data remain conflicting and liver regeneration in animal with fatty liver or steatohepatitis, and otherwise competent leptin signalling, has been reported to be normal by several authors. ${ }^{14-16}$ Also, the amelioration of the obese phenotype and hepatic steatosis in $o b / o b$ mice was not associated with increased capacity for hepatocyte proliferation after acute toxic injury to the liver. ${ }^{12}$ Therefore, it is plausible that impaired regeneration in leptin-deficient or -resistant rodents might be due to factor(s) related to impaired leptin signalling, and not solely to fatty infiltration of the liver. Moreover, leptin regulates important physiological functions such as energy homeostasis, lipid partitioning, maturation and activity of immune and inflammatory cells. The perturbation of any of those might impede the process of liver regeneration.

Another hypothesis implicates the metabolic adaptation to chronic oxidative stress to which $o b / o b$ liver is exposed ${ }^{17}$ as a mechanism that renders mature hepatocytes replicatively senescent. ${ }^{10}$ In this scenario, accumulation of progenitor (oval) cells is seen as an adaptative mechanisms to maintain liver mass in the face of increased hepatocellular loss. Whether this progenitor compartment is recruited and activated to source differentiated hepatocytes after $\mathrm{PH}$ to $\mathrm{ob} / \mathrm{ob}$ livers has not been conclusively examined.

The absence of leptin as a signalling molecule and/or the metabolic consequences of leptin deficiency have been proposed as causal factors for impaired liver regeneration in $o b / o b$ mice. We thus reasoned that correction of either or both of these parameters should stimulate a physiological proliferative response. To test this, we performed, in $o b / o b$ mice, hormone replacement experiments and dietary manipulations aiming at the correction of the obese phenotype, and characterised the effect of these on liver regeneration after a non-lethal $\mathrm{PH}$ procedure (removal of $55 \%$ of the liver mass). Leptin replacement and amelioration of the metabolic syndrome and hepatic steatosis, with or without restitution of normal circulating levels of leptin, did not restore replicative competence to $o b / o b$ livers.

\section{Methods}

\section{Animals, Surgical Procedures, and Tissue Collection}

Female $o b / o b$ mice have been subjected to a $70 \% \mathrm{PH}$ (removal of the anterior right and median lobes) or a $55 \% \mathrm{PH}$ under ether anaesthesia. For the latter, the right anterior lobe was removed and a second ligature was placed in the cleavage of the median lobe to remove the right portion of the median lobe leaving its left portion with its intact vascularisation in situ. At the time of $\mathrm{PH}$ (performed in all mice between 0900 and 1100), a wedge of hepatectomized tissue was fixed in formalin for histological analysis and the remaining portion snap frozen in liquid nitrogen and served as 'prehepatectomy' $(0 \mathrm{~h})$ controls. After surgery, mice were kept on a heating path till complete recovery to avoid hypothermia, and they were then replaced in the animal house with $\mathrm{ad}$ libitum access to water and food unless otherwise specified.

Mice were killed, blood collected and the liver removed 44,72 or $168 \mathrm{~h}$, post-PH. BrdU ( $50 \mu \mathrm{g} / \mathrm{kg})$ was injected $2 \mathrm{~h}$ prior to killing. A wedge of the left posterior lobe was fixed in formalin for histological analyses and the rest of the liver was stored at $-80^{\circ} \mathrm{C}$.

Experimental groups are detailed in Figure 1. For the $70 \% \mathrm{PH}$ experiment, lean mice were used as controls and $o b / o b$ mice were randomly divided into one of the following groups: Control ob/ob underwent $70 \% \mathrm{PH}(n=10)$; ob/ob mice received leptin either by intraperitoneal (i.p.) injections of mouse recombinant leptin (100 $\mu \mathrm{g} / \mathrm{kg}$ body weight, (Sigma) twice daily starting $2 \mathrm{~h}$ prior to $70 \% \mathrm{PH}$ and until killing $(n=6)$, or $2 \mathrm{~h}$ prior to $70 \% \mathrm{PH}$ followed by implantation at the time of $\mathrm{PH}$ of a mini-pump in the subcutaneous tissue between the scapula that continuously delivered leptin at a rate of $300 \mu \mathrm{g} / \mathrm{kg}$ body weight $/ 24$ h $(n=6)$.

In a second experimental setting, $o b / o b$ mice randomly assigned to one of the following groups ( $n=5$ minimum per group) were subjected to a $55 \%$ $\mathrm{PH}: \quad o b / o b$ control had 55\% PH. ob/ob+leptin received recombinant leptin (100 or $250 \mu \mathrm{g} / \mathrm{kg}$ body weight, twice daily by i.p. injection, starting $26 \mathrm{~h}$ prior to $55 \% \mathrm{PH}$ as specifically indicated in the results and figure legends, and continued until killing). Lean mice had a 55\% $\mathrm{PH}$ and served as controls. Additionally, to assess the effect of leptin on regeneration, a group of lean mice was treated with leptin $(250 \mu \mathrm{g} / \mathrm{kg} / \mathrm{twice}$ daily) and regeneration examined 168 after 55\% PH.

In a third experiment designed to test the effect of correction of metabolic phenotype of $o b / o b$ mice on liver regeneration, $o b / o b$ mice received leptin $100 \mu \mathrm{g} / \mathrm{kg}$ body weight-physiological dose-i.p. twice daily starting 3 weeks prior to $55 \% \mathrm{PH}$ and continued until killing. Another group of $o b / o b$ mice were pair-fed the same amount of food as leptin-repleted ob/ob mice for 3 weeks prior to $55 \%$ $\mathrm{PH}$. The last group was pair-fed for 3 weeks prior to $\mathrm{PH}$ and received leptin $(250 \mu \mathrm{g} / \mathrm{kg}$ every $12 \mathrm{~h}$, starting $26 \mathrm{~h}$ prior to $\mathrm{PH}$ and continued till killing). Untreated lean and ob/ob mice underwent a $55 \% \mathrm{PH}$ and served as controls. Lean and ob/ob (control, pair-fed and with long-term leptin replacement) mice were tested for their tolerance to glucose and their response to insulin 7 and 5 days prior to $\mathrm{PH}$, respectively. Glucose (1.5 g/kg body weight) was injected i.p. on $4 \mathrm{~h}$-fasted animals and glucose levels 

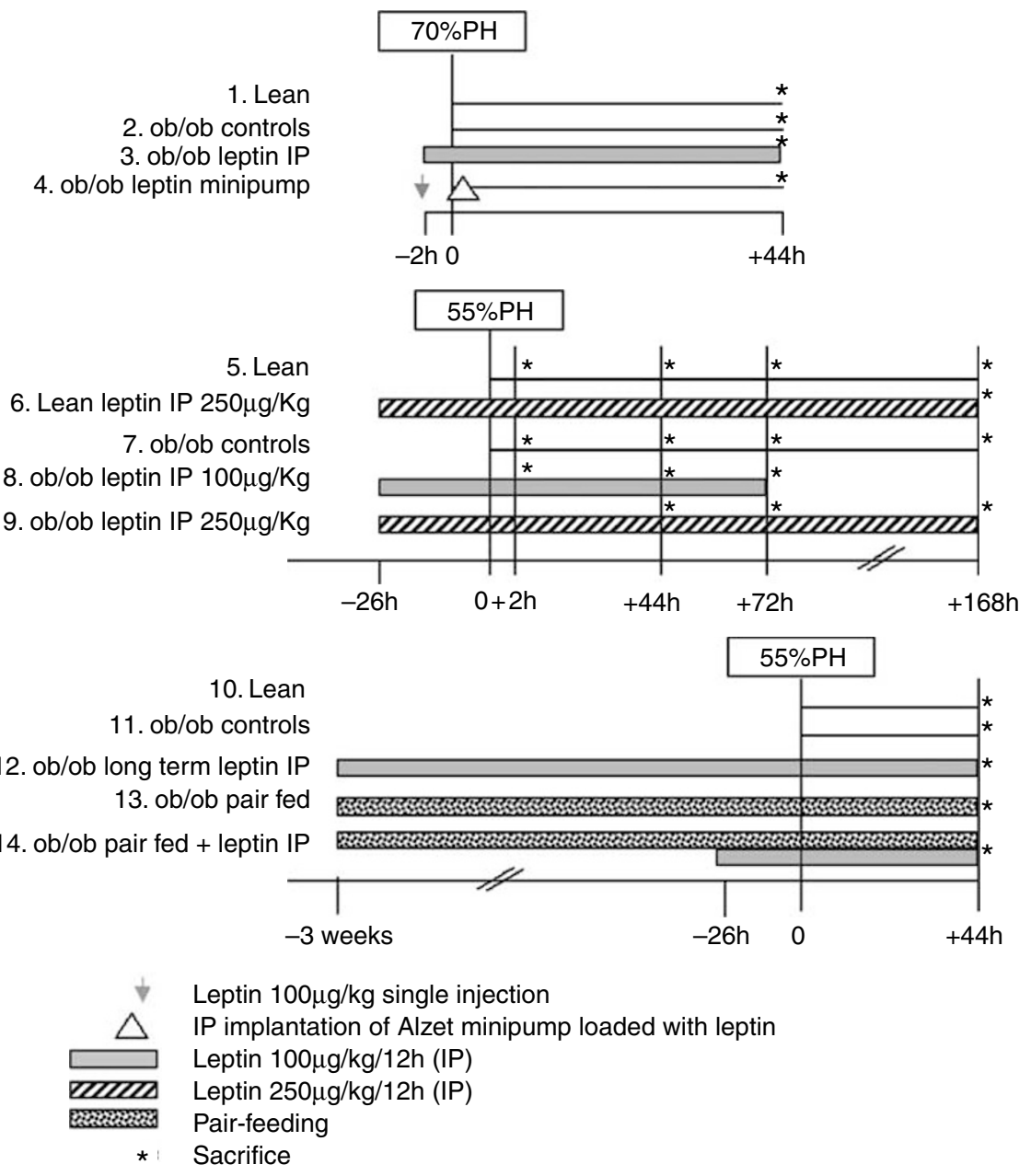

Figure 1 Animal groups and experimental design. Lean or ob/ob mice underwent a partial hepatectomy with removal of 70 or $55 \%$ of the liver mass between 0900 and 1100 and mice were killed at the indicated time points (denoted by the asterisk*). Leptin was injected i.p. at the doses of $100 \mu \mathrm{g} / \mathrm{kg}$ (grey bars) or $250 \mu \mathrm{g} / \mathrm{kg}$ (hatched bars) twice daily starting at the indicated time. Mice in group 4, received a leptin injection $(100 \mu \mathrm{g} / \mathrm{kg}) 2 \mathrm{~h}$ prior to the hepatectomy (arrow) and were implanted an osmotic minipump (Alzet 1003D) that continuously delivered leptin at a rate of $300 \mu \mathrm{g} / \mathrm{kg}$ body weight $/ 24 \mathrm{~h}$ just after the PH (large open arrowhead). Pair-fed mice (dotted bars) received the amount of food consumed by leptin treated $o b / o b$ mice.

monitored $0,15,30,60,90$ and 120 min after the injection. Insulin $(0.5 \mathrm{U} / \mathrm{kg}$ body weight) was administered i.p. after overnight fasting and glucose monitored $0,15,30,45,60$ and $120 \mathrm{~min}$ after the injection. All experiments were initiated on young adult (10-week-old) mice such that all mice underwent hepatectomy between 10 and 13 weeks of age.

\section{Biochemical Analyses}

Leptin concentrations on serum collected at the time of killing were measured by radio-immunoassay (Linco Research, St Charles, MI, USA). Total lipid content was determined as previously described. ${ }^{18}$ Hepatic TNF protein was quantitated by ELISA (mouse TNF Quantikine, R\&D, Minneapolis, MN, USA) on whole-liver homogenates, and hepatic IL-6 mRNA by real-time PCR, as previously described ${ }^{19}$ using the following primers: IL-6 forward: 5'- ctgcaagagacttccatccagtt- $3^{\prime}$; reverse: $5^{\prime}$-ccacggccttccc tacttc-3'; house keeping RPL19 forward: $5^{\prime}$-gaaggt caaagggaatgtgttca-3'; reverse: 5 '-acaagctgaaggcagaca agg- $3^{\prime}$.

\section{Assessment of Hepatocyte Proliferation}

Four markers of liver regeneration were evaluated. (a) The restitution of liver mass was determined as the percentage of regenerated liver mass calculated as follows: hepatic regeneration rate $(\%)=100 \times$ $\{C-(A-B)\} / A$ in which $A$ is the total liver weight at the time of $\mathrm{PH}$ as estimated from the weight of excised liver corresponding to $55 \%$ of the liver mass; $B$ is the excised liver weight; and $C$ is the weight of regenerated liver at the final resection. ${ }^{11}$ To minimise the impact of large variations in lipid content on the estimation of the regeneration rate, total hepatic lipid have been measured, and lipid 
load subtracted from the weight of excised livers (pre- and post-PH) and these values used to calculate the hepatic regeneration rate corrected for lipid content (\%). (b) The number of mitotic figures in hepatocytes (on H\&E-stained sections). (c) DNA synthesis determined by immuno-detection of incorporation of BrdU in newly synthesized DNA. (d) Nuclear expression of the proliferative marker Ki67. For immunodetections, de-paraffinized and re-hydrated sections were heated in citrate buffer ( $\mathrm{pH}$ 6.0) and then incubated for $1 \mathrm{~h}$ at RT with anti-BrdU antibody $^{14}$ or with Ki67 Ab (MIB5 clone, Dako, Glostrup, Denmark, dilution 1/50). Bound antibodies were revealed by anti-mouse Envision (Dako, Glostrup, Denmark). In coded sections from each mouse, mitotic figures in hepatocytes were counted on six non-overlapping high power $(\times 20)$ microscope fields and expressed as mean \pm s.d. per group. BrdU or Ki67 positive and negative hepatocyte nuclei were counted in six non-overlapping highpower $(\times 40)$ microscope fields (with a minimum of 300 hepatocytes counted) and data expressed as positive hepatocyte nuclei $( \pm$ s.d.) per 100 hepatocytes.

To identify biliary cells, hepatic oval cells and intermediate hepatocyte-like cells, we performed immunostaining on formalin fixed and paraffinembedded liver sections using a rabbit polyclonal pan-cytokeratins antibody (Dakocytomation, Glostrup, Denmark). We assessed separately the number of bile ducts and the number cytokeratin (CK) positive cells isolated or forming ductules or ductule-like structures. The later number was regarded as the ductular progenitor cell compartment. Evaluation was performed on portal tracts of similar size and cut perfectly transversally (8-20 portal tracts examined per liver section, 6 sections per experimental group). CK positive cells were counted on coded sections using a $\times 40$ objective equipped with a grid, by two investigators independently.

\section{Results}

\section{Liver Cell Proliferation after PH is Dampened and Delayed in ob/ob Mice}

While well tolerated in lean mice, the classical $70 \%$ $\mathrm{PH}$ induced death in seven out of $10 \mathrm{ob} / \mathrm{ob}$ mice between 18 and $24 \mathrm{~h}$ post-PH. In the three surviving mice, examination of the livers $44 \mathrm{~h}$ post-PH (around the peak for DNA synthesis) showed rare mitosis and BrdU positive nuclei (Figure 2 and Table 1), confirming exquisite sensitivity to liver mass loss and impaired liver regeneration in $o b / o b$ mice. ${ }^{10,12}$ Leptin, administered at the dose of $100 \mu \mathrm{g} / \mathrm{kg}$ every $12 \mathrm{~h}$ i.p. or once i.p. $2 \mathrm{~h}$ prior to $\mathrm{PH}$ followed by implantation of a mini-pump ensuring continuous release of leptin for $48 \mathrm{~h}$, restored circulating leptin at concentrations close to those of control mice (Table 2). However, leptin replacement did not ameliorate the mortality after $70 \% \mathrm{PH}$ (Table 1).

Because the high mortality after $70 \% \mathrm{PH}$ precluded the analysis of hepatic regeneration, we performed a $55 \% \mathrm{PH}$. In lean mice, this procedure was followed by a progressive recovery of liver mass (Figure 3a) and hepatocyte proliferation, as demonstrated by the presence of numerous mitotic figures (Figure 3b), increased BrdU incorporation in hepatocytes (not shown) and high number of Ki67 expressing hepatocytes at 44 and $72 \mathrm{~h}$ after the procedure (Figures 3c, 4a and b). After $168 \mathrm{~h}$, the estimated regeneration rate was $112 \%$ (hyperplasia) associated with persistence of a mitotic activity (Figures 3b, c and 4c) together with some apoptotic

\section{b ob/ob}

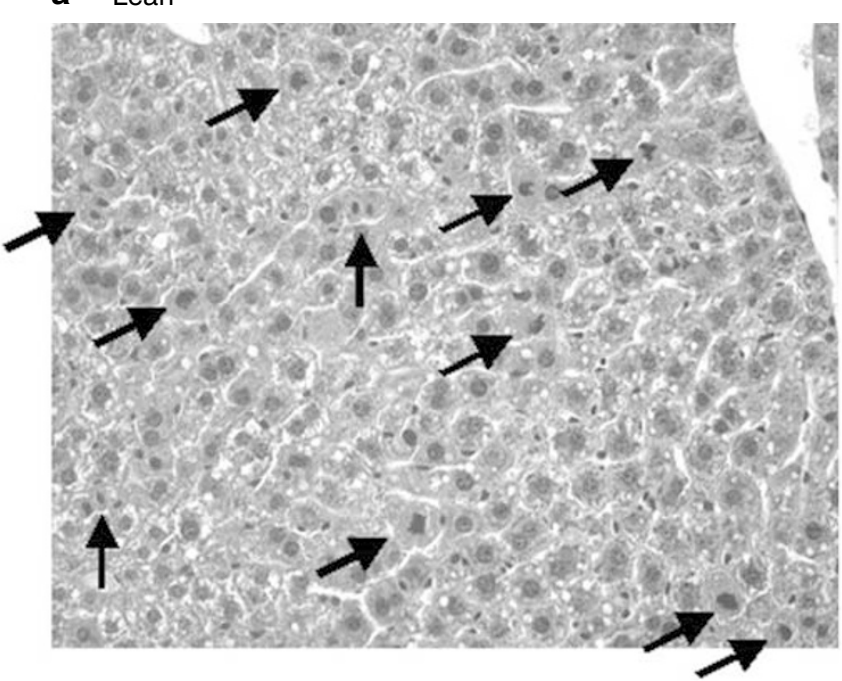

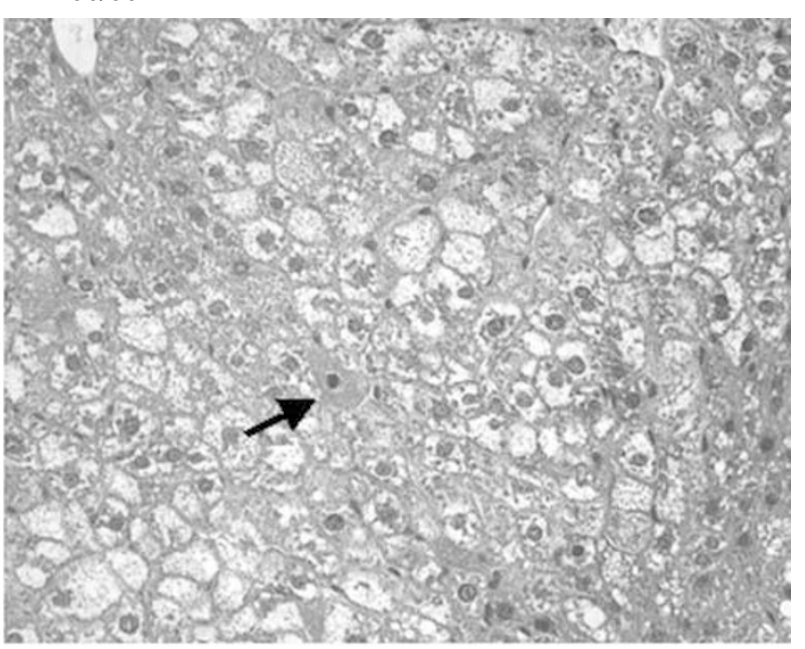

Figure 2 Representative photomicrograph of liver sections of (a) lean mice and (b) ob/ob mice $44 \mathrm{~h}$ after a classical $70 \%$ PH. The arrows denote mitotic figures. Note the presence of multiple mitotic figures in the liver of lean mice and the paucity of mitosis in $o b / o b$ liver. Haematoxylin and eosin staining, original magnification $\times 20$. 
Table 1 Quantification of hepatocyte proliferation $44 \mathrm{~h}$ after a 70\% $\mathrm{PH}$ to lean, $o b / o b$ and leptin-repleted $o b / o b$ mice

\begin{tabular}{|c|c|c|c|c|}
\hline & Lean mice & ob/ob mice & $\begin{array}{l}\text { ob/ob mice+leptin } \\
100 \mu \mathrm{g} / \mathrm{kg} 2 \times / \text { day }\end{array}$ & $\begin{array}{c}\text { ob/ob mice+leptin } \\
\text { mini-pump }\end{array}$ \\
\hline Survival & 6 out of 6 & 3 out of 10 & 2 out of 6 & 1 out of 6 \\
\hline Mitotic figure/HPF ${ }^{\mathrm{a}}$ & $14 \pm 3$ & $<1$ & $<1$ & $<1$ \\
\hline BrdU+ve hepatocyte nuclei $(\%)^{\mathrm{b}}$ & $39 \pm 12$ & $7 \pm 3$ & $5 \pm 2$ & $5 \pm 1$ \\
\hline
\end{tabular}

${ }^{\mathrm{a}}$ Mean \pm s.d. of six non-overlapping high-power $(\times 20)$ field.

${ }^{\mathrm{b}} \mathrm{BrdU}$ positive hepatocytes nuclei per 100 hepatocytes (300 hepatocytes were counted per section).

Table 2 Serum leptin concentrations

\begin{tabular}{|c|c|c|}
\hline Genotype & Treatment & Serum leptin $(\mathrm{ng} / \mathrm{ml})^{\mathrm{a}}$ \\
\hline $\begin{array}{l}\text { Lean mice } \\
o b / o b \text { mice }\end{array}$ & $\begin{array}{l}\text { - } \\
\text { Leptin mini-pump } \\
\text { Leptin } 100 \mu \mathrm{g} / \mathrm{kg} \text { twice daily (start } 26 \mathrm{~h} \text { prior to } \mathrm{PH} \text { ) } \\
\text { Leptin } 250 \mu \mathrm{g} / \mathrm{kg} \text { twice daily (start } 26 \mathrm{~h} \text { prior to } \mathrm{PH} \text { ) } \\
\text { Leptin } 100 \mu \mathrm{g} / \mathrm{kg} \text { twice daily (start } 3 \text { weeks prior to } \mathrm{PH} \text { ) }\end{array}$ & $\begin{array}{c}5.2 \pm 0.9 \\
<1.5 \\
4.2 \pm 0.6 \\
10.8 \pm 6.5 \\
>20 \\
8.5 \pm 2.6\end{array}$ \\
\hline
\end{tabular}

${ }^{\mathrm{a}}$ Serum leptin concentrations were measured $44 \mathrm{~h}$ post-PH and $4 \mathrm{~h}$ after the last injection of recombinant leptin.

hepatocytes (not shown). There was no mortality in this group.

In ob/ob mice, a $55 \% \mathrm{PH}$ induced little mortality (one mouse out of 20 died $18 \mathrm{~h}$ post-PH). The regeneration of liver mass was significantly lower at all time points compared to lean mice such that after $168 \mathrm{~h}$, ob/ob livers had only recovered $40 \%$ of the excised mass (Figure 3a, and Supplementary data). At $44 \mathrm{~h}$ post-PH there were rare and significantly less mitotic figures (Figure $3 \mathrm{~b}$ ), BrdU positive (not shown) or Ki67 positive hepatocyte nuclei than in lean mice (Figures 3c and $4 \mathrm{~d}$ ). These numbers increased at $72 \mathrm{~h}$ but remained significantly less than in lean mice (Figures 3 and $4 \mathrm{e}$ ). After $168 \mathrm{~h}$, rare mitosis and Ki67 were still observed (Figures 3 and 4f). This demonstrates that liver regeneration and hepatocyte proliferation are both dampened and delayed in $o b / o b$ livers.

\section{Effects of Leptin Replacement of Regeneration Induced by a $55 \%$ PH to ob/ob Mice}

To determine whether leptin replacement would improve defective regeneration, $o b / o b$ mice were injected leptin (100 $\mu \mathrm{g}$ or $250 \mu \mathrm{g} / \mathrm{kg}$ body weight) $2 \mathrm{~h}$ prior to $55 \% \mathrm{PH}$ and every $12 \mathrm{~h}$ thereafter $(n=5$ for each leptin dose and time point). Leptin replacement was associated with reduction of food intake and induction of weight loss, and restored normal or supra-normal serum leptin concentrations for mice treated with 100 or $250 \mu \mathrm{g}$ leptin/ $\mathrm{kg}$ body weight, respectively, in the postoperative period (Table 2). Of these 30 mice in leptin-supplemented groups, only two mice died from direct surgical complications. Despite leptin replacement, the numbers of mitotic figures, BrdU positive or Ki 67 positive hepatocyte nuclei $44 \mathrm{~h}$ after $\mathrm{PH}$ were similar to those of untreated $55 \%$ partially hepatectomized ob/ob mice and significantly lower than in lean mice (Figures 3 and 4g). Moreover, the number of mitoses and Ki67 positive hepatocyte nuclei was significantly lower $72 \mathrm{~h}$ post-PH in leptin supplemented $o b / o b$ livers than in those of $o b / o b$ mice (Figures 3 and $4 \mathrm{~h})$. This was associated with a lower liver regeneration rate up to 168 post-PH (Figure 3a). Thus, leptin-replacement did not improve nor accelerate liver regeneration in $o b / o b$ mice, but rather inhibited the delayed phase of hepatocyte proliferation seen in $o b / o b$ livers. Similarly and in accordance with a previous report, ${ }^{20}$ exogenous leptin also dampened liver mass recovery in lean mice (Figure 3a).

\section{TNF Protein and IL-6 mRNA Expression after PH}

In lean mice, we observed a $50 \%$ increase in hepatic TNF protein and an 8 fold upregulation of IL-6 transcript levels $2 \mathrm{~h}$ after $\mathrm{PH}$. Both were at base line levels $44 \mathrm{~h}$ post-PH. In ob/ob mice, hepatic TNF levels were unchanged 2 and $44 \mathrm{~h}$ post-PH, and IL-6 transcript levels were modestly increased (two-fold) $2 \mathrm{~h}$ post-PH. In leptin-repleted mice, TNF protein and IL-6 mRNA were unchanged 2 and $44 \mathrm{~h}$ post-PH, compared to base line levels (Table 3 ).

\section{Effect of the Amelioration of the Metabolic Dysfunction on Liver Regeneration in ob/ob Mice}

Severe insulin resistance and hepatic steatosis are prominent metabolic dysfunctions in $o b / o b$ mice, 
1166
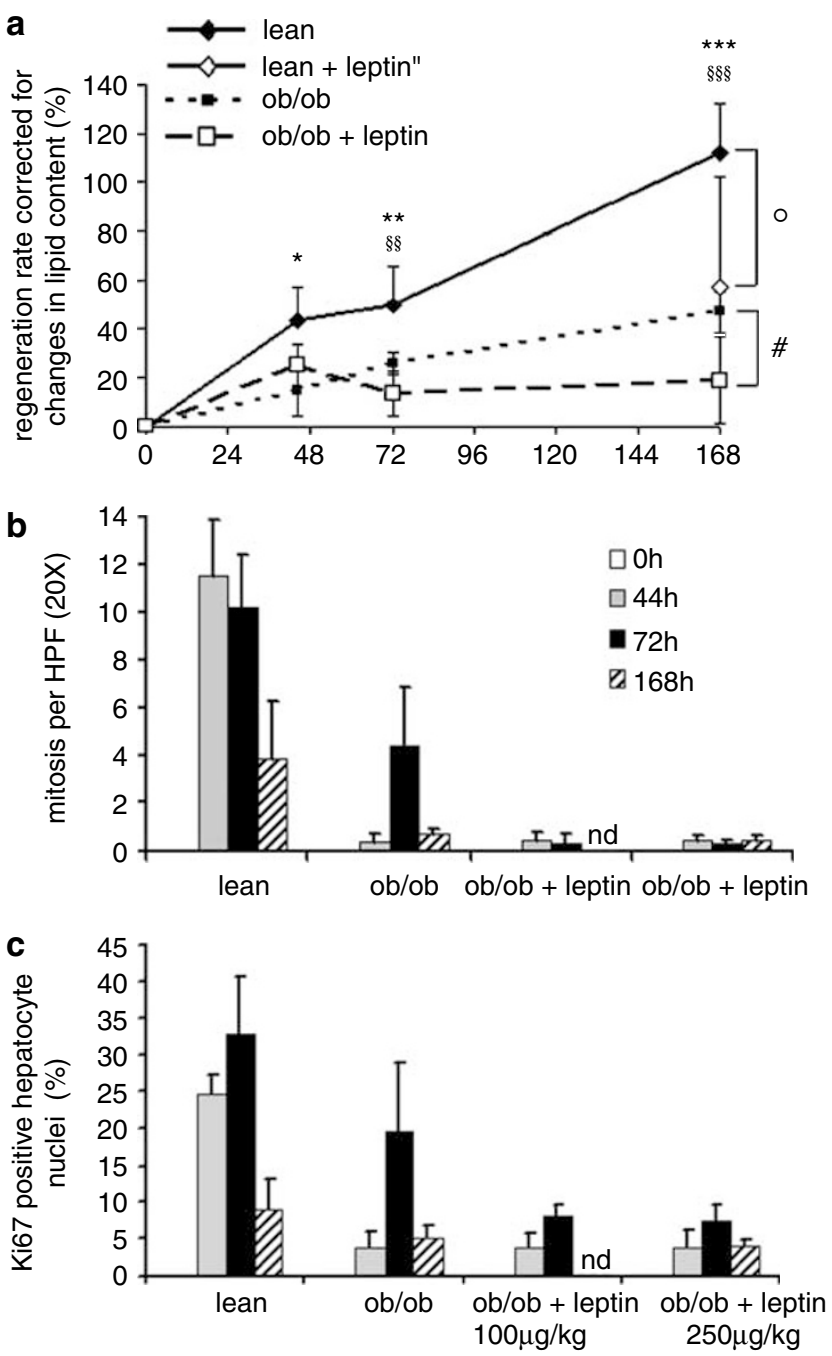

Figure 3 (a) Percentage of new regenerated liver weight corrected for lipid content (regeneration rate) $44 \mathrm{~h}, 72 \mathrm{~h}$ and $168 \mathrm{~h}$ after a $55 \% \mathrm{PH}$ in lean (black diamonds, continuous line), ob/ob (black square, dotted line), leptin-treated lean (open diamond) or leptintreated $o b / o b$ (open square, hatched line) mice. In the leptintreated groups, mice received leptin $250 \mu \mathrm{g} / \mathrm{kg}$ twice daily starting $26 \mathrm{~h}$ prior to $\mathrm{PH} .{ }^{*} P<0.05$, ${ }^{*} P<0.01$ and ${ }^{*} * * P<0.001$ compared to $o b / o b$ mice. ${ }^{\$} P<0.01$ and ${ }^{\$} \$ P<0.001$ compared to leptintreated $o b / o b$ mice. ${ }^{\#} P<0.05$ in leptin-treated versus untreated $o b / o b$ mice. $P=0.005$ for the difference between lean and leptin treated lean mice $168 \mathrm{~h}$ post-PH. Evaluation of hepatocyte proliferation prior to (open bars), $44 \mathrm{~h}$ (grey bars), $72 \mathrm{~h}$ (black bars) or $168 \mathrm{~h}$ (hatched bars) after $55 \% \mathrm{PH}$ in lean mice, $o b / o b$ mice and $o b / o b$ mice treated with leptin 100 or $250 \mu \mathrm{g} / \mathrm{kg}$ as described in Methods. (b) Number of mitotic figures in hepatocytes per field (mean \pm s.d. of six non-overlapping high power $(\times 20)$ fields/section, six sections examined per group) and $(\mathbf{c})$ Ki67 positive hepatocyte nuclei per 100 hepatocytes $(\approx 300$ hepatocytes counted using a $\times 40$ objective equipped with a grid). Mitoses and Ki67 have been counted by two independent investigators in duplicate on coded sections. ND: not determined.

which might inhibit liver cell division. ${ }^{13}$ To ameliorate those, ob/ob mice received leptin $(100 \mu \mathrm{g} / \mathrm{kg}$ twice daily) for 3 weeks prior to and after PH (leptin group). Under this treatment, leptin concentrations in serum were normalised (Table 1), and the daily food intake decreased from $5.9 \pm 0.8 \mathrm{~g}$ to $3.2 \pm 1.1 \mathrm{~g}$.
Another group of ob/ob mice was pair-fed the amount of food consumed by leptin-repleted $o b / o b$ mice for 3 weeks prior to and after 55\% PH (pair-fed group). In addition, a subgroup of pair fed mice received leptin $100 \mu \mathrm{g} / \mathrm{kg}$ twice daily at the time of $\mathrm{PH}$ (pair-fed + leptin group). Compared to control $o b / o b$ mice, which gained $\approx 25 \%$ of their body weight over the 3 weeks period, leptin-repleted and pair-fed ob/ob mice lost $\approx 30$ and $\approx 25 \%$ of their body weight over the same period of time, respectively. Pair feeding and, to a greater extent, longterm leptin administration were associated with decreased fasting blood glucose concentrations and improvement of the metabolic syndrome. This was assessed in vivo by a significant amelioration of glucose tolerance in response to i.p. glucose load and normalisation of blood glucose curves after i.p. insulin challenge (Figure $5 \mathrm{a}$ and $\mathrm{b}$ ). Both leptin treatment and pair feeding induced a clearance of steatosis as demonstrated on histological sections and by the reduction of hepatic lipid content (Figure 5c).

Liver regeneration in response to $55 \% \mathrm{PH}$ was examined in long-term leptin treated and pair-fed $o b / o b$ mice (with or without leptin injections at the time of $\mathrm{PH}$ ). In the pair-fed group, two out of five mice died within $24 \mathrm{~h}$ post-PH. In the remaining three, liver examination $44 \mathrm{~h}$ post-PH showed the absence of mitosis and rare BrdU or Ki67 positive hepatocyte nuclei (Figure 6). Moreover, there were no sign of mitotic activity or DNA synthesis in pairfed $o b / o b$ mice that have been repleted with leptin (Figure 6), although in this group, there was no mortality after PH. Similarly, PH did not induce any significant hepatocyte proliferation in long-term leptin treated $o b / o b$ mice, and this despite prolonged correction of the hormonal defect and amelioration of the metabolic syndrome and hepatic steatosis.

\section{Examination of the Hepatic Progenitor Cell Compartment in Lean and ob/ob Livers after 55\% PH}

It has been shown in several models of acute or chronic liver diseases that progenitor cell populations might be activated as an alternate source for hepatic cells when residual hepatocytes are unable to proliferate to ensure liver regeneration. ${ }^{21,22}$ This process is supposed to involve proliferation of progenitor cells (so-called oval cells) located in the vicinity of the portal area. In order to assess whether such a phenomenon is operating in the liver of $o b / o b$ mice, we searched for sign of expansion and proliferation of the progenitor cell compartment by immunohistochemistry using polyclonal antibody against CK7-19. ${ }^{23}$ CK7-19 is present not only in oval cells and intermediate hepatocyte-like cells but also in biliary cells, which can be identified by their morphology. We assessed separately the number of bile ducts and the number of progenitor cells per 

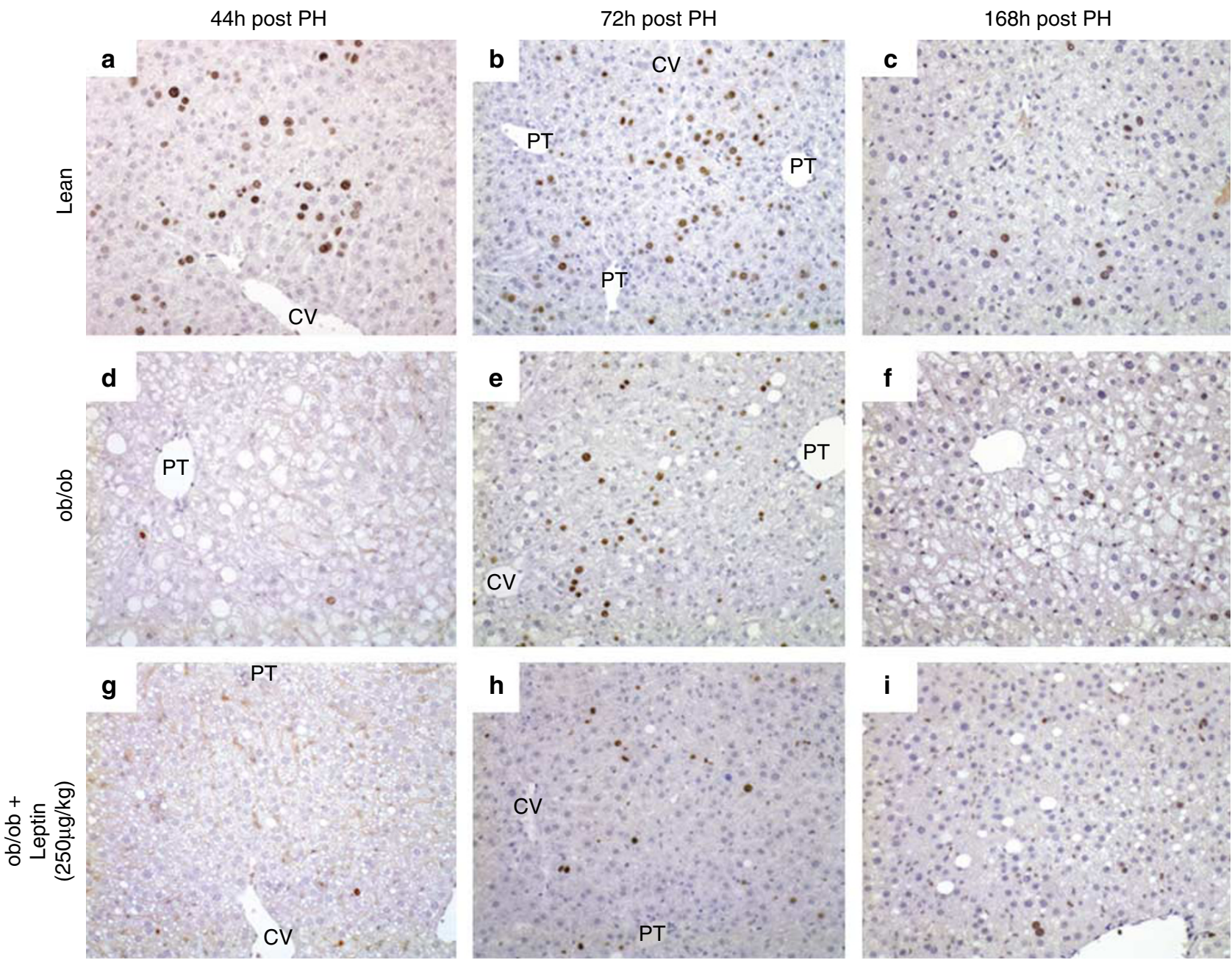

Figure 4 Representative photomicrographs of liver sections from lean (a-c), $o b / o b(\mathbf{d}-\mathbf{f})$ and leptin-treated $o b / o b$ (g-i) mice harvested $44 \mathrm{~h} \mathrm{(a,} \mathrm{d,} \mathrm{g),} 72 \mathrm{~h} \mathrm{(b,} \mathrm{e,} \mathrm{h)} \mathrm{and} 168 \mathrm{~h}(\mathbf{c}, \mathbf{f}, \mathbf{i})$ after $55 \% \mathrm{PH}$ and immunostained with Ki67 antibody. Leptin treated mice received leptin $250 \mu \mathrm{g} / \mathrm{Kg}$ body weight twice daily with the first injection $26 \mathrm{~h}$ prior to PH. CV: central vein, PT: portal tract.

Table 3 Hepatic TNF protein and IL-6 mRNA after 55\% PH

$$
\text { Time post-PH (h) }
$$

\begin{abstract}
Hepatic TNF protein (ng/mg protein)
\end{abstract}
Hepatic IL-6 mRNA/RPL 19 mRNA (arbitrary units)

$\begin{array}{cllc}0 & 63 \pm 6 & 68 \pm 12 & 65 \pm 2 \\ 2 & 92 \pm 5^{* *} & 62 \pm 7 & 60 \pm 5 \\ 44 & 50 \pm 6 & 62 \pm 6 & 56 \pm 5 \\ 0 & 1.0 \pm 0.3 & 0.6 \pm 0.1^{*} & 1.5 \pm 1.4 \\ 2 & 8.4 \pm 2.9^{* *} & 1.6 \pm 1.0 & 1.5 \pm 1.0\end{array}$

${ }^{*} P<0.05$ in $o b / o b$ compared to controls.

${ }^{*} P<0.01$ at $2 \mathrm{~h}$ compared to base line $(0 \mathrm{~h})$.

portal tract of similar size and cut perfectly transversally (8-20 per liver section, 6 sections per experimental group). We also analysed indices of cell proliferation (mitosis and Ki67 expression) at the mesenchymal-parenchymal interface of the periportal areas. In the liver of lean mice, there were rare CK positive cells and one to two bile duct structures per portal tract (Figures 7a and 8). The number of CK7-19 positive cells increased margin- ally 44 or $72 \mathrm{~h}$ post-PH (Figures $7 \mathrm{~b}$ and 8 ) and no mitosis, BrdU incorporation or Ki67 positivity was seen in these cells. This observation confirms that progenitor cell activation leading to lineage generation is not observed during liver regeneration after $55 \% \mathrm{PH}$ in normal lean mice. In accordance with what has been found by others, ${ }^{23}$ the number of CK positive cells, both ductular or ductular-like structures as well as isolated CK7-19 positive cells, was 


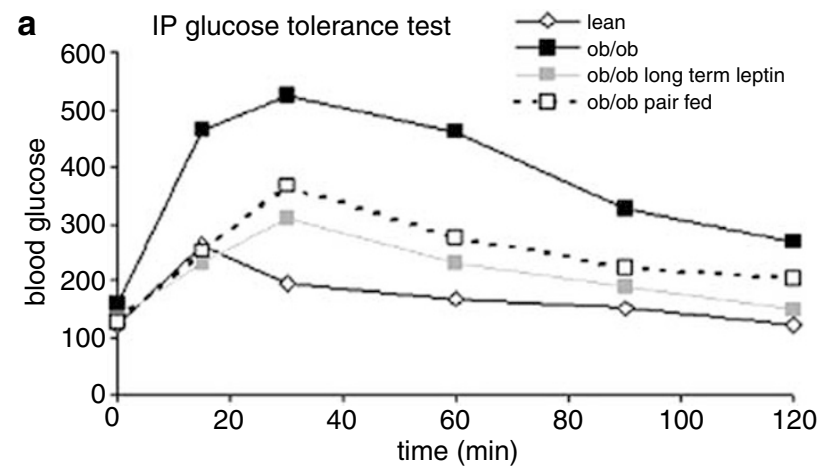

Ki67 expression was seen in CK7-19 positive cells (Figures 7e, f, 4d and e). Thus, although the decreased number in CK positive cells might be compatible with the differentiation of hepatic progenitor cells into more mature hepatocytes, there is no active recruitment or proliferation in the progenitor cell compartment to compensated for impaired hepatocyte proliferation after important and rapid removal of liver mass such as induced by $\mathrm{PH}$ in $o b / o b$ livers.
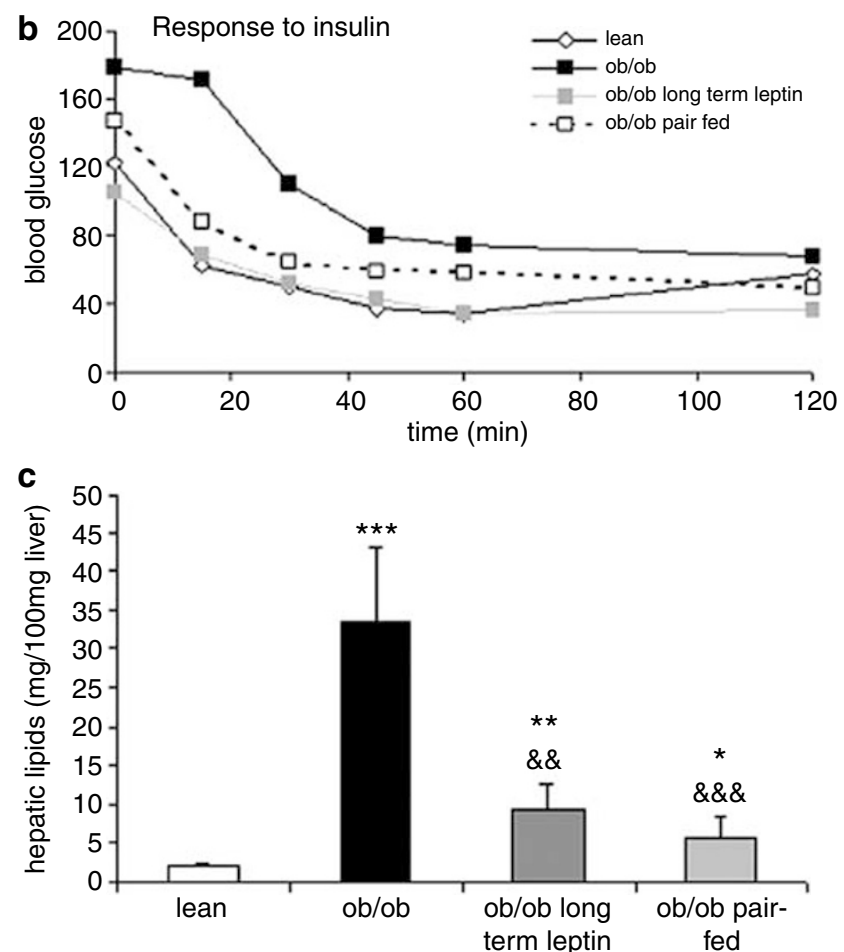

Figure 5 Leptin repletion and food restriction improve glucose tolerance, insulin sensitivity and hepatic steatosis in $o b / o b$ mice. (a) Graph representing the evolution of blood glucose concentrations $(\mathrm{mg} / \mathrm{dl})$ over time after i.p. injection of glucose $(1.5 \mathrm{~g} / \mathrm{kg}$ body weight) on $4 \mathrm{~h}$-fasted animals. (b) Graph representing the evolution of blood glucose concentrations $(\mathrm{mg} / \mathrm{dl})$ at the indicated time points after insulin ( $0.5 \mathrm{U} / \mathrm{kg}$ body weight) injected i.p. after overnight fasting. Mean glucose values obtained in lean mice (open lozenge), $o b / o b$ mice (black square), pair-fed $o b / o b$ mice (open square/dotted line) and leptin-repleted $(250 \mu \mathrm{g} / \mathrm{kg}$ twice daily) $o b / o b$ mice (grey square). (c) Total lipid content was determined on anterior lobes excised at the time of $\mathrm{PH}$ and expressed as mg of lipid by $100 \mathrm{mg}$ of wet liver (mean \pm s.d.) in minimum five mice per group. Data are presented for lean mice (open bar), $o b / o b$ mice (black bar), $o b / o b$ mice receiving leptin $250 \mu \mathrm{g} / \mathrm{kg}$ i.p. twice daily (grey bar) or pair-fed and (hatched bar) for 3 weeks prior to $\mathrm{PH} .{ }^{*} P<0.5,{ }^{*} P<0.01$ and ${ }^{* * *} P<0.001$ compared to lean livers, ${ }^{\& \&} P<0.01$ and ${ }^{\& \& \&} P<0.001$ compared to $o b / o b$ livers.

higher in the liver of $o b / o b$ mice than in lean mice prior to hepatectomy (Figures $7 \mathrm{~d}$ and 8). After $\mathrm{PH}$ (both at 44 and $72 \mathrm{~h}$ ), we found the number of CK7-19 positive cells to be decreased in ob/ob livers compared to the prehepatectomy situation (Figures 7e, $\mathrm{f}$ and 8 ). In addition, no mitosis or

\section{Discussion}

Liver regeneration in leptin-deficient $o b / o b$ mice is impaired. ${ }^{10,12}$ Here, we tested the capacity of leptin replacement to rescue defective regeneration of the $o b / o b$ livers in response to surgical reduction of liver mass (or $\mathrm{PH}$ ). Because the classical $70 \% \mathrm{PH}$ procedure led to unacceptably high mortality $(70 \%)$ in leptin-deficient mice precluding the analysis of the biological response in the remnant liver, we adapted the surgical model and performed a $55 \%$ $\mathrm{PH}$. This procedure reduced to $6.6 \%$ the mortality in $o b / o b$ mice, while there was no mortality in lean littermates. In lean mice, 55\% $\mathrm{PH}$ was followed by proliferation of a significant proportion of the remnant hepatocytes at 44 and $72 \mathrm{~h}$ after $\mathrm{PH}$. By contrast, a proliferative response of weaker magnitude was only observed after $72 \mathrm{~h}$ in $o b / o b$ livers. Impaired regeneration was still observed $168 \mathrm{~h}(7$ days) after surgery with a regenerated liver mass reduced by $60 \%$ compared to lean mice. This demonstrates that liver regeneration was profoundly impaired and delayed in leptin-deficient animals. Administration of recombinant leptin was inefficient in correcting the hepato-proliferative defect. In addition, our data clearly demonstrate that longterm leptin repletion (3 weeks), although sufficient to significantly improve the complex metabolic phenotype of leptin-deficient mice, including obesity, liver steatosis and insulin resistance, failed to permit normal hepatic regenerative process in response to resection of $55 \%$ of the liver mass. Although the schemes for leptin administration we used might not mimic regulations and feedback mechanisms over time, they restored near to physiological concentrations and leptin metabolic actions. This indicates that the consequences of leptin deficiency extend beyond the lack of interaction of leptin with its receptor(s) at the time of $\mathrm{PH}$, consistent with the absence of mitogenic effect of leptin on primary hepatocytes in culture. Rather, our observations support the proposition that life-long leptin deficiency has deeply altered the homeostasis mechanisms that enable the liver to adapt to an acute reduction in functional liver mass and to stimulate its regeneration. Alternatively, as we saw a reduced proliferation in leptin-treated lean mice as well as an inhibition of the delayed phase of proliferation in leptin-repleted $o b / o b$ mice, leptin 

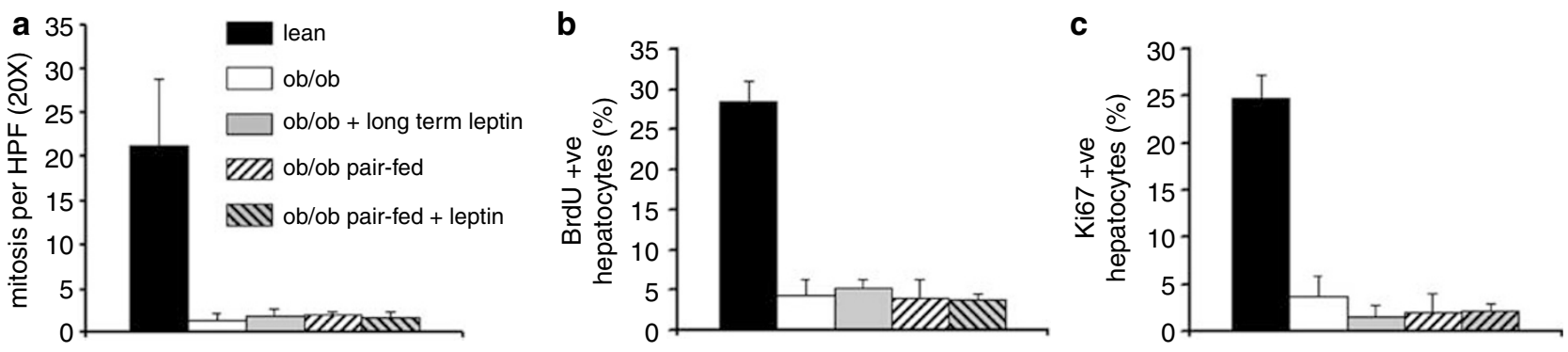

Figure 6 Evaluation of hepatocyte proliferation $44 \mathrm{~h}$ after $55 \% \mathrm{PH}$ in lean mice (black bars), ob/ob mice (open bar), $o b / o b$ mice receiving leptin $250 \mu \mathrm{g} / \mathrm{kg}$ i.p. twice daily for 3 weeks prior to, and after PH (ob/ob long term leptin; grey bar), $o b / o b$ mice pair-fed for 3 weeks prior to, and after PH (black and white hatched bar), or pair-fed mice injected with leptin $250 \mu \mathrm{g} / \mathrm{kg}$ i.p. twice daily starting $26 \mathrm{~h}$ prior to $\mathrm{PH}$ (black and grey hatched bar). (a) Number of mitotic figures in hepatocytes per field (mean \pm s.d. of six non-overlapping high power $(\times 20)$ fields/section, five sections examined per group), (b) BrdU and (c) Ki67 positive hepatocyte nuclei per 100 hepatocytes.
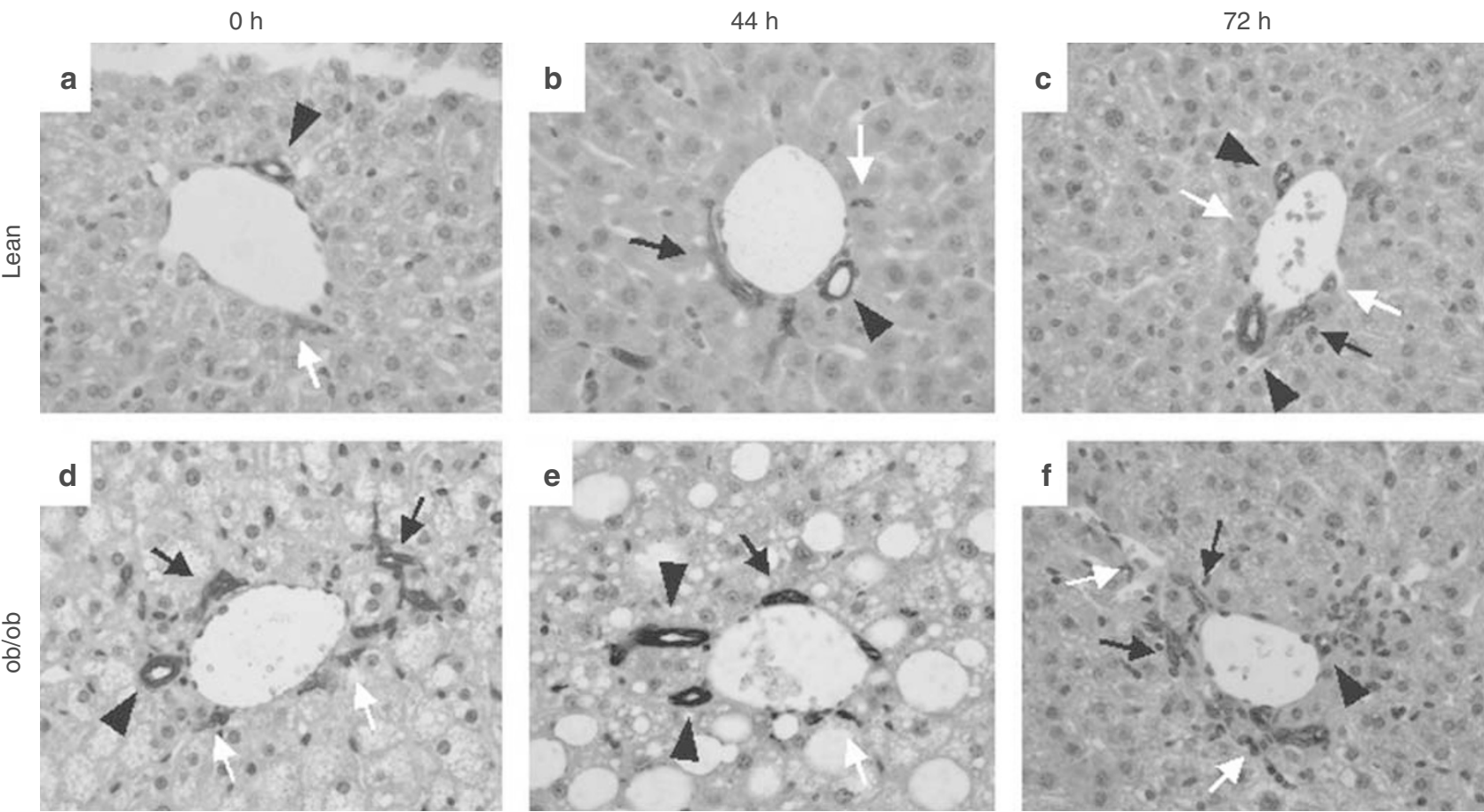

Figure 7 Representative photomicrographs of liver sections from lean (a-c) and $o b / o b$ mice (d-f) $0 \mathrm{~h} \mathrm{(a,} \mathrm{d),} 44 \mathrm{~h}(\mathbf{b}, \mathbf{e})$ and $72 \mathrm{~h}$ after $55 \%$ $\mathrm{PH}(\mathbf{c}, \mathbf{f})$ and immunostained with polyclonal CK7-19 antibody. Arrow heads pointing towards bile ducts; putative progenitor cells, isolated or organised as pseudoductular structures are denoted by white and black arrows respectively. Note that there are no mitotic figure in the CK positive cells and in the immediate vicinity of the portal tract.

might exert an inhibitory effect on liver regeneration. Indeed, Shteyer et al ${ }^{20}$ have suggested supraphysiological doses of leptin $(1 \mathrm{mg} / \mathrm{kg})$ prevent hepatic regeneration in normal mice.

There are no developmental abnormalities in the liver of $o b / o b$ mice and they reach the adult age with steatotic but otherwise morphologically normal liver suggesting that leptin per se is not necessary for normal organogenesis of the liver. It is therefore reasonable to assume that alteration of proliferative capacity of $o b / o b$ liver may not be dependent on leptin but rather on secondary changes caused by leptin deficiency. First, the normal wave of TNF and IL-6 upregulation believed to be important signalling molecules for stimulation of regeneration was blunted in $o b / o b$ mice and not restored by leptin administration. These observations are in contradiction with previous data showing that leptin supplementation improved both cytokine production and hepatocyte proliferation after toxic hepatic necrosis. ${ }^{12}$ The nature of the injurious stimuli may explain the discrepancy between the two models: $\mathrm{PH}$ induces a hyper-acute reduction of liver mass with no cellular lesion or inflammation in the remaining lobes. By contrast, $\mathrm{CCl}_{4}$ induces extensive necrosis and hepatocyte proliferation is integrated to a complex wound healing response including sustained inflammatory reaction, stimulation of fibrogenesis and fibrolysis and hepatic cell proliferation. Therefore, although being probably of similar molecular nature, the source, the timing and the magnitude of the stimuli for regeneration are 


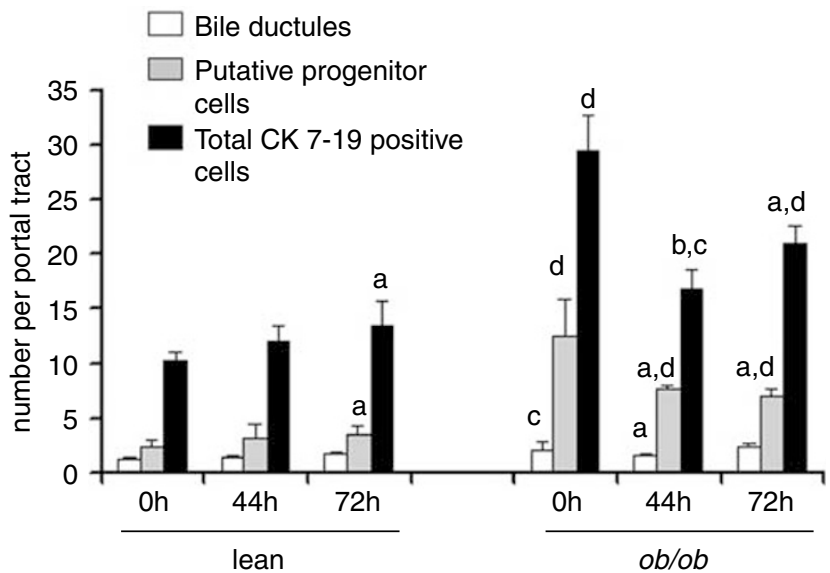

Figure 8 Graph representing the mean number \pm s.d. of bile ducts (open bars), putative progenitor cells (grey bars) and total CK positive cells (black bars) per portal tract. Eight to 20 small portal tracts of similar size and cut perfectly transversally have been counted per section. Six sections at each time point and from each genotype have been examined by two investigators, independently and on coded sections. ${ }^{\mathrm{a}} P<0.05,{ }^{\mathrm{b}} P<0.01$ compared to time 0 of the respective genotype, ${ }^{\mathrm{c}} P<0.01$, ${ }^{\mathrm{d}} P<0.001$ in $o b / o b$ compared to lean at the same time point.

likely to vary between the two models, with a prominent role of leptin-regulated inflammatory reaction in the second. Second, ob/ob mice exhibit a complex metabolic phenotype (obesity, diabetes, hepatic steatosis) partly resulting from hyperphagia, due to the loss of the central control of appetite, as well as from the loss of leptin control on lipid and glucose metabolic pathways. ${ }^{6-9,24}$ Replicating cells consume energy generated by mitochondrial $\beta$ oxidation. ${ }^{1}$ Thus, in leptin-deficient livers, insulin resistance, altered lipid metabolism and mitochondrial dysfunction leading to ATP depletion ${ }^{10,17,25}$ could render the cells unable to meet increased energy demands required for the proliferative process. The metabolic abnormalities were significantly corrected by restriction of dietary intake, and even more so by long-term administration of recombinant leptin. Indeed, in these two groups we observed a reduction in body weight gain, a depletion of hepatic lipid stores, and a significant amelioration of the metabolic syndrome (reduced hyperglycaemia and hyper-insulinaemia, as well as improved glucose tolerance and insulin sensitivity). These ameliorations have been shown to be associated to increased fatty acid oxidation, ATP synthesis and antioxidant defences. ${ }^{24}$ However, this did not allow liver regeneration. Thus, the regenerative response was not rescued by correction of the metabolic phenotype whether or not associated with hormone replacement. Therefore, reduced adaptative capacity of $o b / o b$ hepatocytes to face metabolic stress, as a consequence of altered intrahepatic metabolism, does not appear as a the only factor limiting the proliferative rate of the hepatocytes.

Progenitor cell activation has been proposed as a facultative and alternative source for hepatocytes when mature hepatocytes are unable to enter the cell cycle and replicate. ${ }^{3,5,26}$ The recruitment of this progenitor compartment has been exemplified in several rats models associating a stimulus for proliferation (such as $\mathrm{PH}$ ) and inhibition of cell proliferation with compounds such as acetylaminofluorene, diethylnitrosamine or retrorsine..$^{5,22,27}$ As reported by others, ${ }^{28}$ there is an increased number of putative progenitor cells (CK-7 positive cells in the periportal area) in the liver of $o b / o b$ mice, in basal conditions. It has been suggested by Diehl and coworkers that such accumulation of hepatic progenitor cells might represent a compensatory or adaptative response of $o b / o b$ livers to maintain liver mass in the face of increased cell death due to chronic oxidative injury and replicative senescence of $o b / o b$ hepatocytes. ${ }^{23,28}$ It has also been suggested that expansion and differentiation of the progenitor cell compartment may contribute to the regeneration of $o b / o b$ livers after $\mathrm{PH}^{23}$ To analyse whether progenitor cell compartment expends after $\mathrm{PH}$, we monitored the number of cells and indices of cell proliferation in the progenitor compartment. After $\mathrm{PH}$ to $o b / o b$ mice, the number of oval cells decreased, and at none of the time points examined were seen mitoses or Ki67 expression in CK-7 positive oval cells. These observations lead to two propositions. First, the decreased number of oval cells in the liver of ob/ob mice after $\mathrm{PH}$ is compatible with a differentiation of these progenitor cells into more mature hepatocytes. If confirmed, such differentiation may partly contribute to the restoration of hepatocellular mass of $o b / o b$ livers after $\mathrm{PH}$. Second, as no significant mitotic activity was seen in the progenitor cell compartment, it is unlikely that proliferation of oval cells might represent an alternative mechanism compensating for impaired capacity of mature hepatocytes to regenerate in response to an acute loss of liver mass.

In conclusion, survival of $o b / o b$ mice after $70 \%$ $\mathrm{PH}$ is severely compromised and is not improved by leptin repletion. After a $55 \% \mathrm{PH}$, hepatic cell proliferation and liver regeneration were deeply impaired in $o b / o b$ mice. Our results conclusively show that liver regeneration in $o b / o b$ livers was not restored by leptin replacement, nor after significant amelioration of the metabolic syndrome and hepatic steatosis, with or without restitution of normal circulating levels of leptin. All this strongly suggests that leptin does not directly signal on hepatocytes to allow cell cycle entry and the regenerative process and that leptin replacement, alone or together with amelioration of the obese phenotype, is not sufficient to correct the proliferative defect. It therefore appears that life-long deficiency in this pleiotropic hormone has altered regulatory functions necessary for normal regeneration of the liver after acute mass resection. Much remains to be done to identify whether the defect involves regulation of leptindependent signal transduction, regulation of metabolic or immuno-inflammatory mechanisms. The 
progenitor cell compartment is increased in $o b / o b$ livers; however, after $\mathrm{PH}$ cell proliferation in this compartment is not obvious. Although differentiation of pre-existing progenitor cells into mature hepatocytes remains to be demonstrated, it can be concluded that expansion of the progenitor cell compartment is not activated to rescue defective hepatocyte proliferation after $\mathrm{PH}$ in $o b / o b$ mice.

\section{Acknowledgements}

We are thankful to Mrs Christine De Saeger and Martine Stevens for excellent technical assistance. This work was supported by the Belgian 'Fonds National de la Recherche Scientifique' (convention no. 3.4507.04), by Grant 05/10-328 (action de recherche concertée de la direction de la recherche scientifique de la communauté française de Belgique) and by a grant from Astra-Zeneca Belgium. IL is Research Associate with the Belgian 'Fonds National de la Recherche Scientifique'.

\section{References}

1 Michalopoulos GK, DeFrances MC. Liver regeneration. Science 1997;276:60-66.

2 Fausto N. Liver regeneration. J Hepatol 2000;32(Suppl): 19-31.

3 Fausto N, Campbell JS. The role of hepatocytes and oval cells in liver regeneration and repopulation. Mech Dev 2003;120:117-130.

4 Fausto N. Liver regeneration and repair: hepatocytes, progenitor cells, and stem cells. Hepatology 2004;39: 1477-1487.

5 Thorgeirsson SS. Hepatic stem cells in liver regeneration. FASEB J 1996;10:1249-1256.

6 Halaas JL, Gajiwala KS, Maffei M, et al. Weightreducing effects of the plasma protein encoded by the obese gene. Science 1995;269:543-546.

7 Halaas JL, Boozer C, Blair-West J, et al. Physiological response to long-term peripheral and central leptin infusion in lean and obese mice. Proc Natl Acad Sci USA 1997;94:8878-8883.

8 Friedman JM, Halaas JL. Leptin and the regulation of body weight in mammals. Nature 1998;395:763-770.

9 Burcelin R, Kamohara S, Li J, et al. Acute intravenous leptin infusion increases glucose turnover but not skeletal muscle glucose uptake in ob/ob mice. Diabetes 1999;48:1264-1269.

10 Yang SQ, Lin HZ, Mandal AK, et al. Disrupted signaling and inhibited regeneration in obese mice with fatty livers: implications for nonalcoholic fatty liver disease pathophysiology. Hepatology 2001;34: 694-706.

11 Selzner M, Clavien PA. Failure of regeneration of the steatotic rat liver: disruption at two different levels in the regeneration pathway. Hepatology 2000;31:35-42.
12 Leclercq IA, Field J, Farrell GC. Leptin-specific mechanisms for impaired liver regeneration in ob/ob mice after toxic injury. Gastroenterology 2003;124: 1451-1464.

13 DeAngelis RA, Markiewski MM, Taub R, et al. A highfat diet impairs liver regeneration in C57BL/6 mice through overexpression of the NF-kappaB inhibitor, IkappaBalpha. Hepatology 2005;42:1148-1157.

14 Picard C, Lambotte L, Starkel P, et al. Steatosis is not sufficient to cause an impaired regenerative response after partial hepatectomy in rats. J Hepatol 2002; 36:645-652.

15 Rao MS, Papreddy K, Abecassis M, et al. Regeneration of liver with marked fatty change following partial hepatectomy in rats. Dig Dis Sci 2001;46:1821-1826.

16 Rao MS, Peters JM, Gonzalez FJ, et al. Hepatic regeneration in peroxisome proliferator-activated receptor alpha-null mice after partial hepatectomy. Hepatol Res 2002;22:52-57.

17 Yang S, Zhu H, Li Y, et al. Mitochondrial adaptations to obesity-related oxidant stress. Arch Biochem Biophys 2000;378:259-268.

18 Leclercq IA, Farrell GC, Field J, et al. CYP2E1 and CYP4A as microsomal catalysts of lipid peroxides in murine nonalcoholic steatohepatitis. J Clin Invest 2000;105:1067-1075.

19 Leclercq IA, Farrell GC, Sempoux C, et al. Curcumin inhibits NF-kappaB activation and reduces the severity of experimental steatohepatitis in mice. J Hepatol 2004;41:926-934.

20 Shteyer E, Liao Y, Muglia LJ, et al. Disruption of hepatic adipogenesis is associated with impaired liver regeneration in mice. Hepatology 2004;40:1322-1332.

21 Wang X, Foster M, Al Dhalimy M, et al. The origin and liver repopulating capacity of murine oval cells. Proc Natl Acad Sci USA 2003;100:11881-11888.

22 Sell S. Heterogeneity and plasticity of hepatocyte lineage cells. Hepatology 2001;33:738-750.

23 Roskams T, Yang SQ, Koteish A, et al. Oxidative stress and oval cell accumulation in mice and humans with alcoholic and nonalcoholic fatty liver disease. Am J Pathol 2003;163:1301-1311.

24 Liang CP, Tall AR. Transcriptional profiling reveals global defects in energy metabolism, lipoprotein, and bile acid synthesis and transport with reversal by leptin treatment in ob/ob mouse liver. J Biol Chem 2001;276:49066-49076.

25 Chavin KD, Yang S, Lin HZ, et al. Obesity induces expression of uncoupling protein-2 in hepatocytes and promotes liver ATP depletion. J Biol Chem 1999; 274:5692-5700.

26 Alison MR, Golding M, Sarraf CE. Liver stem cells: when the going gets tough they get going. Int J Exp Pathol 1997;78:365-381.

27 Petersen BE, Zajac VF, Michalopoulos GK. Hepatic oval cell activation in response to injury following chemically induced periportal or pericentral damage in rats. Hepatology 1998;27:1030-1038.

28 Yang S, Koteish A, Lin H, et al. Oval cells compensate for damage and replicative senescence of mature hepatocytes in mice with fatty liver disease. Hepatology 2004;39:403-411.

Supplementary Information accompanies the paper on the Laboratory Investigation website (http:// www.nature.com/labinvest) 